\title{
Time-compressed speech test in adults with and without central auditory processing disorders
}

\author{
Larissa Gonçalves Turcatto ${ }^{1}$ \\ https://orcid.org/0000-0003-1353-4100 \\ Renata Coelho Scharlach ${ }^{2}$ \\ https://orcid.org/0000-0002-8567-3401 \\ Joel de Braga Junior ${ }^{1}$ \\ https://orcid.org/0000-0001-6500-9581 \\ Maria Madalena Canina Pinheiro ${ }^{2}$ \\ https://orcid.org/0000-0003-1726-9703
}

Universidade Federal de Santa Catarina UFSC, Curso de Fonoaudiologia, Florianópolis, Santa Catarina, Brasil. Universidade Federal de Santa Catarina UFSC, Departamento de Fonoaudiologia, Florianópolis, Santa Catarina, Brasil.

This project was carried out in the Speech-Language-Hearing Program at the Universidade Federal de Santa Catarina UFSC, Florianópolis, Santa Catarina, Brasil.

Conflict of interests: Nonexistent

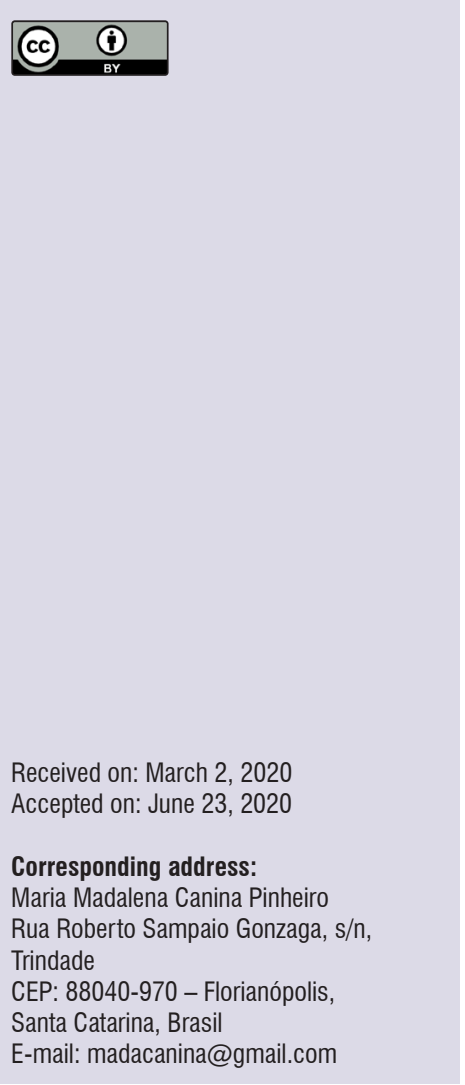

\section{ABSTRACT}

Purpose: to analyze and compare the performance in the time-compressed speech test and the auditory behavior of adults with and without central auditory processing disorders.

Methods: an observational, analytical, cross-sectional study with a total of 40 people of both genders aged 18 to 35 years participating in the study. They were submitted to anamnesis, basic audiological assessment, and a core battery of tests for central auditory processing - including the dichotic digits test (binaural integration), frequency pattern test, and time-compressed speech test (TCST). Based on the results of the dichotic digits and frequency pattern tests, the subjects were divided into two groups, with and without central auditory processing disorders. The auditory behavior was assessed with the Scale of Auditory Behavior (SAB) questionnaire. The Mann-Whitney and Fisher's exact tests were used for the statistical analysis, setting the significance level at $p<0.05$.

Results: no difference in performance was found between the groups regarding the ears. There was a difference between the groups only in the time-compressed speech test with monosyllable stimuli in the left ear $(p=0.026)$. Monosyllables were the words that resulted in most errors.

Conclusion: it was verified that only the list of stimuli influenced the performance, differing the individuals with and without central auditory processing disorders. There was an association of auditory behavior, analyzed with the SAB questionnaire, with the performance in the TCST with the list of monosyllables. It is suggested that this list be used when assessing adults by the time-compressed speech test.

Keywords: Auditory Perception; Auditory Tests; Hearing; Adult; Hearing Disorder 


\section{INTRODUCTION}

The central auditory processing (CAP) is the capacity of our nervous system to recognize, interpret, and process auditory stimuli - i.e., comprehend sound information ${ }^{1}$. There is a series of auditory skills that cooperate to the understanding of acoustic information, namely: sound localization and lateralization, auditory discrimination, selective attention, figure-ground, auditory closure, and temporal resolution, ordering and masking? .

One's difficulty in comprehending auditory information is not always caused by hearing loss. It may be a consequence of the central auditory processing disorder (CAPD), which occurs when the person has a deficit in one or more of the abovementioned auditory skills. In general, people with CAPD present such complaints as difficulties regarding memory, hearing in noise, understanding both verbal and nonverbal sound information, inattention, and learning problems, involving reading and writing ${ }^{3}$

The special behavioral tests that assess the CAP auditory skills are divided into groups: monaural low-redundancy, binaural integration, dichotic hearing, and temporal processing tests. A core battery of tests employed to assess the CAP must include one test of each of these groups, and at least one of them must have nonverbal stimulus ${ }^{1,2}$.

The monaural low-redundancy tests are characterized by their verbal stimuli that undergo time, frequency, and duration changes. These manipulations degrade the stimuli that are presented to the patient. In some tests, the stimuli can be presented along with competing noise ${ }^{4}$ - these tests are sensitive to brainstem alterations ${ }^{5}$. The superior olivary complex is the important structure of the stapedial reflex arc involved in auditory skills ${ }^{6}$, such as auditory attention to continuous sounds, separating an auditory signal from the background noise ${ }^{7}$, and sound localization ${ }^{6-8}$.

In the current battery of behavioral tests for adults, the monaural low-redundancy tests included are the speech in noise, filtered speech, and time-compressed speech test (TCST). All of these assess the auditory closure skill, which enables the person to understand sound information even when parts of the stimulus are missing - i.e., when the signal is degraded ${ }^{1,4}$.

The TCST has a modified duration parameter i.e., the words presented (monosyllables and disyllables) are compressed into a shorter time, making the message more difficult to be understood ${ }^{9,10}$. The spectral characteristics of the original signal are preserved, but the phonetic information is presented in a shorter temporal interval ${ }^{11}$. This test was first proposed in $1972^{12}$, while its Brazilian Portuguese version for adults became standard and normative in $2007^{13}$. The authors' purpose was to develop a Brazilian Portuguese monaural low-redundancy test with an altered duration pattern.

It has already been used in research with children and older adults ${ }^{10,11,14,15}$. However, few studies in Brazil $9,13,16$ involve the administration and observation of TCST in adults. This study is necessary to contribute and add to knowledge concerning the use of this instrument in the clinical practice. Thus, the present research aimed to analyze and compare the performance in the timecompressed speech test and the auditory behavior of adults with and without central auditory processing disorders.

\section{METHODS}

This comparative, descriptive, observational, crosssectional study was submitted to and approved by the Human Research Ethics Committee of the Universidade Federal de Santa Catarina, Brazil, under evaluation report number 2.008.562.

The population of the study comprised 40 individuals of both genders aged 18 to 35 years. Some individuals were recruited at the CAP assessment outpatient center, while others were university students in the speech-language-hearing program.

The following aspects were listed as inclusion criteria: age range from 18 to 49 years; auditory thresholds within normality standards bilaterally ${ }^{17}$; type A tympanometric curve bilaterally ${ }^{18}$; Brazilian Portuguese spoken as first language; absence of oral language alterations and neurological impairments reported by the individuals; no previous musical experience.

After the individuals signed the informed consent form (ICF), they were submitted to anamnesis and basic audiological assessment. They also answered the Scale of Auditory Behavior (SAB) questionnaire and underwent three special behavioral tests from the core CAP battery - Dichotic Digits Test (DDT) in the binaural integration task, frequency pattern test (FPT), and time-compressed speech test (TCST). The DDT and FPT special tests were used to form the groups because they are cited in studies as the ones with the most sensitivity and specificity ${ }^{19}$, besides being used in national studies as auditory screening tests ${ }^{20-22}$. 
Based on the results of the special tests (DDT and FPT), the individuals were divided into two groups:

- Group 1, comprising 20 individuals with normal results in the DDT and FPT and acoustic reflexes present $^{18}$ in all frequencies tested.

- Group 2, comprising 20 individuals with altered results in the DDT binaural integration task and/or FPT, possibly presenting an absence of acoustic reflexes ${ }^{18}$.

It should be highlighted that both groups had the same schooling level - in both G1 and G2, 19 individuals had unfinished higher education, and one had a bachelor's degree.

The basic audiological assessment included the anamnesis, meatoscopy, pure-tone threshold audiometry, speech audiometry, and acoustic immittance. In the meatoscopy, the otoscope used was the 3000 model manufactured by Heine.

The pure-tone threshold audiometry and speech audiometry were conducted with an AC 40 model audiometer manufactured by Interacoustics. The patient was placed in an acoustically treated booth, with TDH39 earphones. In the audiometry, the frequencies tested ranged from $250 \mathrm{~Hz}$ to $8000 \mathrm{~Hz}$. In the speech audiometry ${ }^{23}$, the speech recognition threshold (SRT) and speech recognition index (SRI) were researched to assess the individuals' skills to detect and recognize speech $^{23}$.

The acoustic-immittance meter used for such measures was the AT235 manufactured by Interacoustics, with a $226 \mathrm{~Hz}$ probe tone. The tympanometric curves were traced and the contralateral acoustic reflexes were tested at the frequencies of 500 $\mathrm{Hz}, 1000 \mathrm{~Hz}, 2000 \mathrm{~Hz}$, and $4000 \mathrm{~Hz}$. The individuals who presented acoustic reflex alterations could not join Group 1.

After these procedures, the SAB questionnaire, with 12 auditory behavior-related questions, was administered. Each participant read the questions and chose the answers that best corresponded to their situation. This questionnaire has 12 CAP-related questions, with a score ranging from 12 to 60 points. After being administered, the answers given by each participant were added to reach a total performance. The normality standard adopted holds the score of 46 points as a typical auditory behavior; hence, values lower than this indicate risk for CAPD ${ }^{24}$.

The DDT is a dichotic hearing test that assesses the figure-ground skill for verbal sounds. The task performed in this research was of binaural integration.
A total of 20 sequences with four numbers each were presented; after the participant had heard 10 number sequences, the earphones were inverted. The participant was asked to repeat the numbers they heard, not necessarily in order. The normality standard for the DDT was $95 \%$ or more of correct answers ${ }^{4}$.

The FPT, in its turn, is a test that assesses the temporal ordering auditory skill for nonverbal sounds ${ }^{4}$. The Musiek version ${ }^{25}$ was used, which is made up of 30 items, presented binaurally, with low frequency at $880 \mathrm{~Hz}$ and high frequency at $1122 \mathrm{~Hz}$. Each item of the test has three frequency tones lasting $150 \mathrm{~ms}$, while the intervals in-between tones are of $200 \mathrm{~ms}$. In the naming task, each participant reproduced the order in which they heard the sequence. The normality standard adopted was performance equal or superior to $76 \%$ of correct answers ${ }^{4}$.

The TCST is a monaural low-redundancy test that assesses auditory closure skills. It has four lists of stimuli, each of them with 50 phonetically balanced words - two (lists one and two) with monosyllabic words, and two (lists three and four), with disyllable words. Lists one and two have 33 equal words and 17 different ones; lists three and four have the same words in different orders. The test was administered following the order in the lists of stimuli and the ears to which they were presented - i.e., first, list one was presented to the right ear; then list two, to the left ear; list three, to the right ear; and list four, to the left ear. All the words were compressed by $60 \%$. The authors suggest the normality standard superior or equal to $90 \%$ of correct answers ${ }^{13}$.

The DDT binaural integration task and the TCST were administered using the material in the CAP assessment manual ${ }^{4}$, which presents the behavioral tests recorded in Moving Picture Experts Group 1 Audio Layer 3 (MP3). Tracks six, seven, eight, and nine (TCST) and 12 (DDT) were used. For the FPT, the test proposed by Musiek ${ }^{25}$ was used.

The three tests were presented in TDH39 supraaural earphones, at $50 \mathrm{~dB} \mathrm{SL}$ in the three-frequency mean of 500,1000 , and $2000 \mathrm{~Hz}$, in an acoustically treated booth, using an AC 40 model two-channel audiometer, manufactured by Interacoustics, attached to a Dell Inspiron 155000 notebook.

After being collected, the data were entered into an Excel Office 2016 spreadsheet. Afterward, they underwent inferential/analytical descriptive analysis with the SPSS software for Windows, version 13.0, using the Mann-Whitney and Fisher's exact tests. A 
descriptive statistical analysis of the SAB questionnaire and DDT and FPT tests was conducted. Then, the TCST performance was analyzed according to ear and list of stimuli, per group. In the sequence, the groups were compared according to the list of stimuli and ear. Also, the words with the greatest number of errors per ear and list of stimuli were analyzed, without distributing by the groups. The words mistaken more than 10 times in the TCST, both in the mono- and disyllable lists, were counted. Lastly, it was verified whether there was an association between the TCST and he SAB in all the participants. For this analysis, the monosyllable TCST analysis for the right ear was added to the left one; the same procedure was done with the disyllable analysis.

The Mann-Whitney test was used to verify the association between the ears, list of stimuli, and groups. The variables studied were considered to have an association when the $p$-value was equal or inferior to $0.05(p \leq 0.05)$.

The Fisher's exact test was used to verify the association between the categorical variables (normal and altered) of the SAB with monosyllable and disyllable TCST (right plus left), and with the TCST, according to list of stimuli. It should be emphasized that in the TCST, when the patient had an alteration in one ear, they were already considered altered. The association was verified when the $p$-value was equal or inferior to 0.05 $(p \leq 0.05)$.

In all statistical tests, when the $p$-value was within these criteria, an asterisk $\left(^{*}\right)$ was placed beside the number.

\section{RESULTS}

The population studied comprised 40 people - two males (5\%) and 38 females (95\%) - aged 18 to 35 years, mean age 21 years and six months.

The descriptive statistical analysis of the data found in the SAB questionnaire and DDT and FPT auditory behavioral tests are presented in Table 1, per group and total sample.

Table 1. Descriptive statistics of the scale of auditory behavior questionnaire, dichotic digits test, and frequency pattern test per group

\begin{tabular}{ccccc}
\hline & & Mean/SD & Median & Min-Max \\
\hline \multirow{2}{*}{ SAB (n) } & Group 1 $(n=20)$ & $47.2 \pm 5.9$ & 47.5 & $37-57$ \\
& Group 2 $(n=20)$ & $42.4 \pm 8.1$ & 44 & $22-44$ \\
& Total $(n=40)$ & $44.8 \pm 7.4$ & 45 & $22-57$ \\
\hline \multirow{2}{*}{ DDT RE (\%) } & Group 1 $(n=20)$ & $99.3 \pm 1.3$ & 100 & $96-100$ \\
& Group 2 $(n=20)$ & $97.2 \pm 4.4$ & 100 & $85-100$ \\
& Total $(n=40)$ & $98.2 \pm 3.4$ & 100 & $85-100$ \\
\hline \multirow{2}{*}{ DDT LE (\%) } & Group 1 $(n=20)$ & $99.6 \pm 0.91$ & 100 & $97.5-100$ \\
& Group 2 $(n=20)$ & $97 \pm 6$ & 100 & $77.5-100$ \\
FPT (\%) & Total $(n=40)$ & $98.3 \pm 4.4$ & 100 & $76.6-100$ \\
& Group 1 $(n=20)$ & $89.5 \pm 7.9$ & 88.6 & $36.6-83.3$ \\
& Group 2 $(n=20)$ & $57.1 \pm 13.1$ & 56.7 & $36.6-100$ \\
\hline
\end{tabular}

Captions: $n=$ number of participants; $S D=$ standard deviation; Min-Max= Minimum-maximum; $S A B=$ scale of auditory behavior; DDT RE $=$ dichotic digits test in the right ear; DDT LE = dichotic digits test in the left ear; FPT = frequency pattern test

As shown in Table 1, the median of the score in the $S A B$ questionnaire was higher in $\mathrm{G} 1$, a pattern observed also in the results obtained in the FPT. On the other hand, the performance in the DDT had the same median in both groups.
The descriptive statistical analysis of the findings from the TCST per ear and list of words is given in Table 2, while Figure 1 presents the number of individuals per group that had an alteration in the TCST per list of stimuli. 
Table 2. Descriptive statistics of the time-compressed speech test in the groups by list of stimuli and ear

\begin{tabular}{|c|c|c|c|c|c|}
\hline & & Mean/SD (\%) & Median (\%) & Min-Max (\%) & p-value \\
\hline \multirow{4}{*}{ Group $1(n=20)$} & TCST mono RE & $88.6 \pm 4$ & 89 & $78-94$ & \multirow{2}{*}{0.516} \\
\hline & TCST mono LE & $91.6 \pm 4.1$ & 92 & $84-100$ & \\
\hline & TCST dis RE & $92.6 \pm 4.5$ & 92 & $84-100$ & \multirow{2}{*}{0.643} \\
\hline & TCST dis LE & $92.4 \pm 4.9$ & 92 & $82-100$ & \\
\hline \multirow{4}{*}{ Group $2(n=20)$} & TCST mono RE & $87.4 \pm 3.9$ & 87 & $78-94$ & \multirow{2}{*}{0.516} \\
\hline & TCST mono LE & $88.2 \pm 4.6$ & 89 & $82-96$ & \\
\hline & TCST dis RE & $90.6 \pm 4.5$ & 92 & $82-98$ & \multirow{2}{*}{0.643} \\
\hline & TCST dis LE & $91.8 \pm 2.6$ & 92 & $86-98$ & \\
\hline \multirow{4}{*}{ Total $(n=40)$} & TCST mono RE & $88 \pm 4$ & 88 & $78-94$ & \multirow{2}{*}{0.850} \\
\hline & TCST mono LE & $89.9 \pm 4.7$ & 90 & $82-100$ & \\
\hline & TCST dis RE & $91.6 \pm 3.9$ & 92 & $82-100$ & \multirow{2}{*}{0.532} \\
\hline & TCST dis LE & $92.1 \pm 3.9$ & 92 & $82-100$ & \\
\hline
\end{tabular}

Mann-Whitney U Test

Captions: $\mathrm{n}=$ number of participants; $\mathrm{SD}=$ standard deviation; Min-Max = minimum-maximum; TCST mono RE = time-compressed speech test with monosyllables in the right ear; TCST mono LE = time-compressed speech test with monosyllables in the left ear; TCST dis RE = time-compressed speech test with disyllables in the right ear; TCST dis LE $=$ time-compressed speech test with disyllables in the left ear

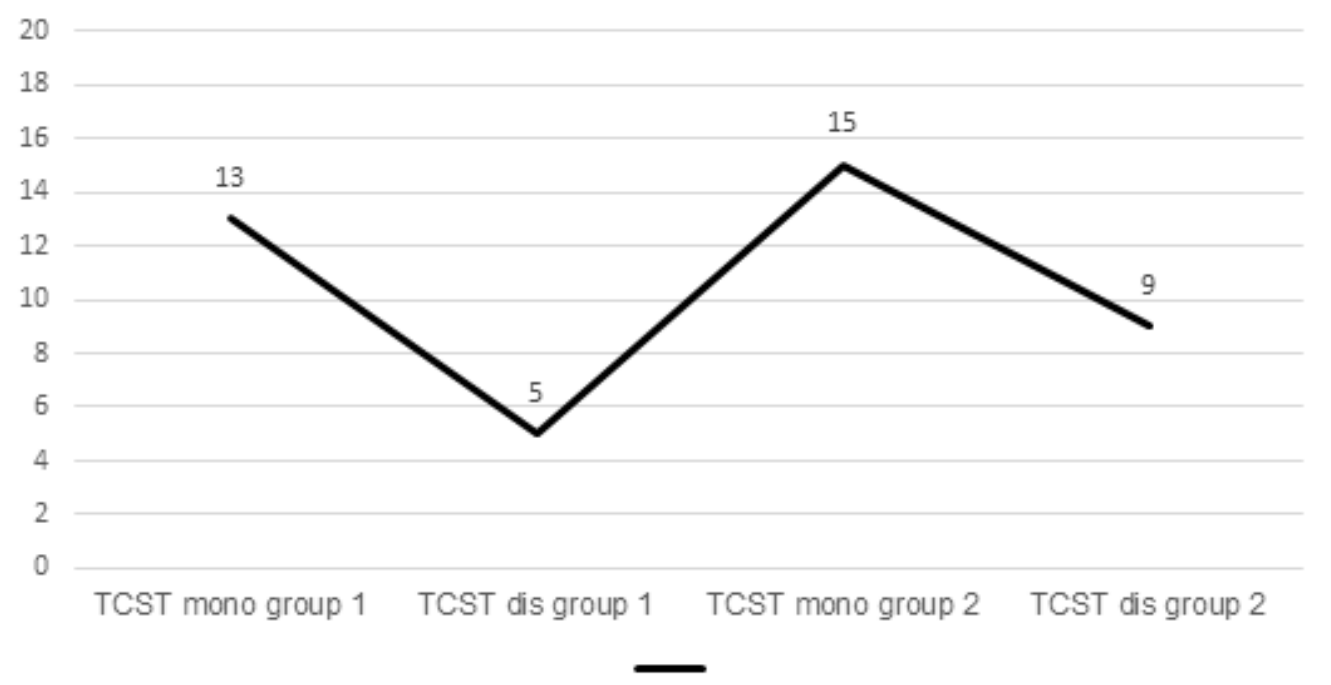

Captions: $\mathrm{n}=$ number of participants; TCST mono = time-compressed speech test with monosyllables; TCST dis = time-compressed speech test with disyllables

Figure 1. Number distribution of individuals with alteration in the time-compressed speech test by group and list of stimuli

The analysis of Table 2 reveals that there is no difference in TCST performance regarding the ears. As for Figure 1, it is observed that, in both groups, the monosyllabic words resulted in the worst performance.

Next, Table 3 is presented, which shows an association between the groups regarding the ears and lists of monosyllable and disyllable words.
Table 3. Association between groups by ear and list of stimuli of the time-compressed speech test

\begin{tabular}{cc}
\hline & p. value \\
\hline TCST mono RE G1 X TCST mono RE G2 & 0.279 \\
TCST mono LE G1 X TCST mono LE G2 & $0.026^{*}$ \\
TCST dis RE G1 X TCST dis RE G2 & 0.273 \\
TCST dis LE G1 X TCST dis LE G2 & 0.590 \\
\hline
\end{tabular}

Mann-Whitney U Test

Captions: $\mathrm{n}=$ number of participants; TCST mono RE = time-compressed speech test with monosyllables in the right ear; TCST mono LE = timecompressed speech test with monosyllables in the left ear; TCST dis RE $=$ timecompressed speech test with disyllables in the right ear; TCST dis LE $=$ timecompressed speech test with disyllables in the left ear 
It was verified in Table 3 that there was a difference between the groups only in the list of monosyllabic stimuli, in the left ear.

The monosyllabic and disyllabic words with the highest rates of errors made by the participants are demonstrated in Figure 2, shown separately by ear.

In the TCST with monosyllables in the right ear, the words with most errors were "pau" (90\% of errors), "cru" (70\% of errors), and "grão" (65.4\% of errors). In the left ear, the words with most errors were "pau" (72.5\% of errors), "pé" (57.7\% of errors), and "traz"
(57.7\% of errors). As for the disyllable words in the right ear, the ones with most errors were "cravo" (42.5\% of errors) and "grito" ( $47.5 \%$ of errors). In the left ear, the most mistaken words were "caro" (52.5\% of errors), and "grito" (37.5\% of errors).

Lastly, Fisher's test was used to verify the association of the TCST per ear and presentation list with the $S A B$ questionnaire, regardless of the group to which the individuals belonged. An association was verified between the SAB performance and the TCST with the list of monosyllabic stimuli ( $p$-value: $\left.0.026^{\star}\right)$.

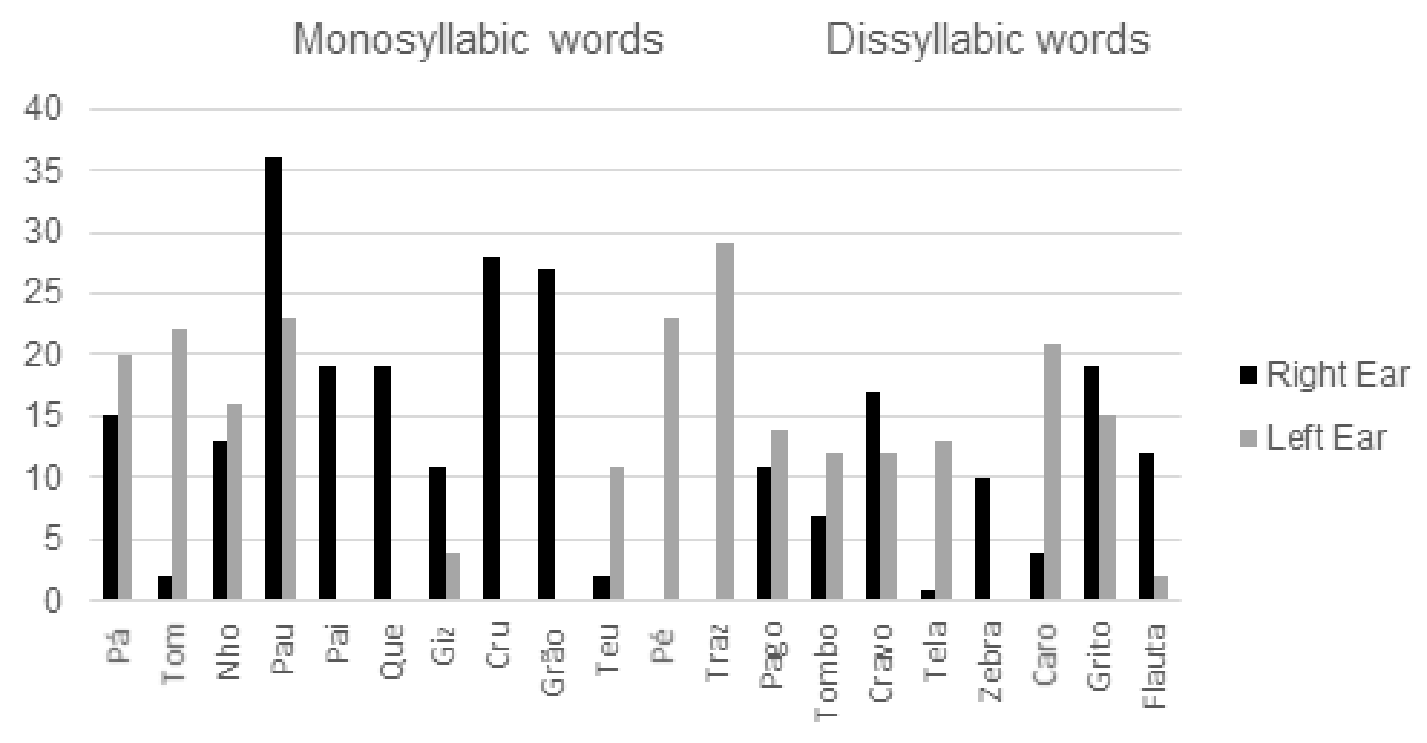

Legend: $n=$ number of participants

Figure 2. Number distribution of monosyllabic and disyllabic Portuguese words with most errors in the time-compressed speech test

\section{DISCUSSION}

In this study, most of the population were females. The literature researched did not report a relationship between gender and better performance in the TCST. Therefore, the greater number of female participants was not a problem for the analysis ${ }^{26,27}$.

In addition to behavioral tests, the literature recommends that questionnaires be used to complement the diagnosis of CAPD ${ }^{28-30}$. Research conducted with adults verified significant correlations between the CAP behavioral tests and a questionnaire ${ }^{28}$. A study ${ }^{29}$ that administered an SAB-based questionnaire and CAP screening states that using self-perception questionnaires with students was an adequate instrument to differentiate the groups studied; it found a CAPD risk score in $85.2 \%$ of the participants with school difficulties. In another study ${ }^{30}$, which administered questionnaires and five
CAP behavioral tests, the authors verified that the use of questionnaires aided in decision-making. Also, they were sensitive to detect problems and help in the clinical assessment of CAP. In the same study, of the behavioral tests used, the FPT and DDT were the ones that most contributed to distributing the groups, correctly classifying $59.3 \%$ of the participating children.

The SAB questionnaire has been used to complement the CAP assessment and provide a simple and quick auditory functioning measurement. By means of this instrument, it can be inferred whether the individual has CAPD-related difficulties ${ }^{24}$. In the present research, the score achieved by $\mathrm{G} 1$ in the $\mathrm{SAB}$ agrees with the findings in the literature ${ }^{24}$, which reports that results higher than 45 points in this questionnaire indicate possible normality in the CAP tests. The median shows a score of 44 points for G2, indicating 
risk for CAPD and/or language alterations. Although the study was conducted with adults and the reference paper make it normative for children, the data in this study corroborate the literature. Hence, the lower the total SAB score, the greater the possibility of the individual having auditory skills alterations (Table 1).

In this research, the DDT performance in G2 had a slight disadvantage when compared to G1. Nevertheless, both groups presented mean values within the normality standards suggested for the test ${ }^{4}$ (Table 1). It is believed that this is due to the DDT stimuli having high predictability and the adults' already having a matured corpus callosum ${ }^{31}$.

The FPT was the test used as a group distribution criterion that most detected alterations; the difference in performance between the groups was quite significant. A study - which used a core battery of behavioral tests (FPT, DDT, filtered speech, and competing sentences test) to assess their sensitivity and specificity both isolated and in combination - showed that the FPT isolated presented the best results for CAP assessment sensitivity, followed by the DDT. In combination, the DDT and FPT are the ones that increase the sensitivity $^{19}$. Given the findings in this study, it is observed that the tests used to divide the population studied into groups agree with what is indicated in the literature.

The time-compressed speech test, although created in $1972^{12}$, was translated in Brazil only in $2007^{13}$ and made available for clinical practice in $2011^{4}$. Hence, few studies in the national literature approach this test. The study that established the TCST norms for adults in Brazil ${ }^{13}$ suggests $90 \%$ of correct answers in all lists of stimuli as the normality standard. Despite that, in the TCST with monosyllables compressed in $60 \%$, the mean performance found is $88 \%$ of correct answers in both ears. In this study, the mean performance in the right ear of G1 in the list of monosyllabic words, as well as in both ears of G2, was below $90 \%$. As for the disyllables list, the performance of both groups corroborates the findings in normally hearing individuals without CAPD complaints ${ }^{13}$ (Table 2). As seen in Figure 1 , regardless of the group, the list of monosyllables was the most difficult for the individuals to hear.

A study was conducted in the Malayalam language - spoken by 38 million people in southern India -, which found a mean performance in the monosyllable and disyllable TCST between 85 and $90 \%$ of correct answers for both normally hearing children and adults $^{10}$. In the American language, the normality for monosyllables and disyllables is $82 \%$ of correct answers ${ }^{32}$.
It should be noted that in the other languages the normality standard admits performances lower than $90 \%$ of correct answers.

In the present study, the subjects' performance in the TCST with disyllable stimuli turned out better than with monosyllabic stimuli, regardless of the group to which they belonged. The words with the most errors were the monosyllabic ones (Table 2). This finding was also present in a study conducted with young adults, which verified worse performance with monosyllabic stimuli in both the right and left ears ${ }^{15}$.

In the TCST studies in other languages, there are reports of the opposite happening - monosyllabic words obtained more correct answers in relation to the disyllable ones. Therefore, it is important to know the linguistic characteristics of each language in which the test was standardized ${ }^{10,33,34}$.

The abovementioned findings of the present study can be explained by many monosyllables' differing only in one phoneme. For instance, "pau" and "tau"; such a similarity in sound and articulation can contribute to the errors made by the individuals. Even though many disyllable words differ in only one phoneme, they are longer words with more sound and semantic information; hence, they are stimuli that can be better understood, resulting in a greater number of correct answers.

In this research, no difference was found in the TCST performance between the ears, either in the monosyllabic or disyllabic stimuli, for G1, G2, and total participants (Table 2). These findings corroborate other studies that also administered the TCST ${ }^{9,13,15}$. A study with young adults ${ }^{16}$ did not verify differences in the TCST performance with monosyllabic stimuli; however, the right ear had a better performance with the disyllable stimuli. The authors report that such a result was not expected since the hemispherical differences occur in the processing of speech sounds for dichotic hearing. In the monotic tests, both the ipsilateral and contralateral pathways of the auditory system are activated. This mechanism neutralizes the laterality effect and leads to a similar performance between the two ears.

Regarding the association between groups, a difference was found only in the TCST with monosyllables in the left ear (Table 3). Since there was also an association only between the list of monosyllables and the SAB performance, the idea of using only the list of monosyllables in the clinical practice is reinforced, as it was the one with the most errors in the altered group, 
besides having a result compatible with the questionnaire and other tests in the battery. The TCST is quite an extensive test, which makes it not much feasible in clinical practice. Using only the list of monosyllables reduces the time it takes to be administered, ensuring a more reliable result.

In the adults, the monaural low-redundancy tests are usually not the most altered ones in the battery because they assess regions whose maturation occurs in the first two years of life ${ }^{35}$.

Monaural low-redundancy tests such as the TCST assess degraded speech comprehension in the brainstem. When the signal processing is altered in the brainstem, other auditory skills are also expected to be impaired - e.g., figure-ground and temporal ordering, which are analyzed in upper regions of the auditory pathway5.

When analyzing all the monosyllabic and disyllable words that resulted in errors, it was observed that some of them had similar characteristics (Figure 2). Of the 20 words with most errors in the TCST with monosyllables and disyllables, 14 began with voiceless phonemes five with [t] (tom, teu, traz, tombo, and tela); five with [p] (pá, pau, pai, pé, and pago); four with [k] (que, cru, cravo, and caro); one with [f] (flauta). Only five of those words began with a voiced phoneme - two had in common the initial sound with a palatal articulation: [3] (giz) and [n] (nhô); two with a velar initial phoneme: [g] (grão and grito); one with a linguodental-articulated initial phoneme: [z] (zebra). Most of the errors occurred when the words began with voiceless phonemes - i.e., sounds produced without vibrating the vocal folds ${ }^{36}$. As they have no trace of sound, they may have hindered the words from being understood.

Another factor that called the attention regarding the words with most errors was that seven of them had a consonant cluster (i.e., a complex onset) (cru, grão, traz, cravo, zebra, grito, and flauta) - six with vibrant liquids, and one with lateral liquid. The consonantal clusters have a complex syllabic structure ${ }^{37}$; in these cases, consonant-consonant-vowel (CCV). In such complex structures, the liquids may have sometimes been auditorily imperceptible, to the point of being a difficulty factor in understanding the words. These findings corroborate a study that administered the TCST in older adults ${ }^{15}$ and verified that the plosive phonemes and the consonantal clusters with / $\mathrm{r} /$ and /// are more difficult to be understood as the speech speed increases.
It is important to know the words that are constantly mistaken when the individuals perform the TCST because it can help to choose words for new adaptations and validations of the test. In Brazil, a study ${ }^{9}$ adapted and validated a new reduced version of the disyllable TCST, with 25-word lists for each ear. The authors report that there were fewer errors in the reduced version than in the original one; however, the most mistaken words are not mentioned. Nevertheless, it was observed that the words "pago", "flauta", "zebra", and "tela" were included in the reduced version - which were the ones with most errors in the present study. These data reinforce the importance of more studies with the TCST.

In this research, the participants were university students, and their socioeconomic level was not researched. However, a study found differences due to socioeconomic levels in the performance in a temporal processing test ${ }^{38}$. Thus, it is suggested that future research investigates this variable.

The present study furnished knowledge regarding the TCST in individuals with and without CAPD. It was verified that using the list of disyllables was not a good predictor of either normality or alteration in the population studied; hence, only the list of monosyllables is indicated for clinical practice. It is suggested that, besides the battery of behavioral tests, a standardized questionnaire be used for a better diagnosis.

It is recommended that the theme of future research be on administering the TCST in combination with other monaural low-redundancy tests to verify which of them has greater sensitivity.

\section{CONCLUSION}

Comparing the individuals with and without CAPD, it was verified that only the list with monosyllabic stimuli in the TCST revealed a difference between the groups, especially the left-ear list. There was no difference regarding the ears in the groups. The list of monosyllables resulted in more errors, and the words with most errors began with voiceless phonemes. There was an association between the auditory behavior (analyzed with the $S A B$ questionnaire) and the performance in the TCST with the list of monosyllables. It is suggested that this list be used in time-compressed speech assessments in adults. 


\section{REFERENCES}

1. Pereira LD, Frota S. Avaliação do processamento auditivo: testes comportamentais. In: Boéchat EM, Menezes PL, Couto CM, Frizzo ACF, Scharlach RC, Anastacio ART (orgs). Tratado de Audiologia. 2 ed. Rio de Janeiro: Guanabara Koogan Ltda; 2015, p. 489-97.

2. American Speech-Language-Hearing Association (ASHA). (central) auditory processing disorders [Technical Report]. 2005. Disponível em: http:// www.asha.org/policy/TR2005-00043/ acessado em: 19 de outubro de 2019.

3. Carvalho NG, Ubiali T, Amaral MIR, ColellaSantos MF. Procedures for central auditory processing screening in schoolchildren. Braz J Otorhinolaryngol. 2019;85(3):319-28.

4. Pereira LD, Schochat E. Testes auditivos comportamentais para avaliação do processamento auditivo central. Ed. Pró-Fono; 2011.

5. Bellis TJ. Interpretation of central auditory assessment results. In: Bellis TJ (ed). Assessment and management of central auditory processing disorders in the education setting: form Science to practice. 2 a ed. San Diego: Singular Publisching Group; 2003. p.267-478.

6. Carvalho RMM. O efeito do reflexo estapediano no controle da passagem da informação sonora. In: Schochat E (org). Processamento auditivo - série atualidades em Fonoaudiologia. Lovise Ed.; 1996. p. 57-73.

7. Simmons FB. Perceptual theories of middle ear muscle function. J Acoust Soc. 1962;34:1524-24.

8. Iguchi $\mathrm{Y}$, Ogawa $\mathrm{Y}$, Tada $\mathrm{Y}$, Kodoma N. Binaural interaction of stapedius reflex. Acta Otolaryngol (Stockh). 1996;116(524):33-5.

9. Folgearini J, Goulart L, Silva D, Vellozo F, Mezzomo C, Garcia M. Time-compressed speech test: adaptation and validation. Rev. CEFAC. 2016;18(6):1294-301.

10. Prabhu $P$, Rasheed $M$, Dinesh $T$. The factors affecting the perception of malayalam time compressed speech in children and young adults. J Phonet and Audiol. 2016;2(1):1-5.

11. Dias JW, McClaskey CM, Harris KC. Time-Compressed Speech Identification is predicted by auditory neural processing, Perceptuomotor speed, and executive functioning in younger and older listeners. JARO. 2019;20(1):73-88.
12. Beasley D, Schwimmer S, Rintelmann W. Intelligibilty of timecompressed CNC monosyllables. J Speech Hear Res. 1972;15(2):340-50.

13. Rabelo CM, Schochat E. Time - compressed speech test in brazilian portuguese. Clinics. 2007;63(3):261-72.

14. Padilha FYOMM, Pinheiro MMC. Study on the application of the time-compressed speech in children. CoDAS. 2017;29(5):1-7.

15. Arceno RS, Scharlach RC. Time-compressed speech test in the elderly. CoDAS. 2017;29(5):218-25.

16. Rabelo CM, Rocha-Muniz CN, Schochat E. Ongoing maturation in the time-compressed speech test. Clinics. 2018;73(8)1-8.

17. Lloyd LL, Kaplan H. Audiometric interpretation: a manual of basic audiometry. 2 th ed. Baltimore: University Park Press; 1978.

18. Jerger J. Clinical experience with impedance audiometry. Arch Otolaryngol. 1970;92(4):311-24.

19. Musiek FE, Chermak GD, Weihing J, Zappulla M, Nagle S. Diagnostic accuracy of established central auditory processing test batteries in patients with documented brain lesions. J Am Acad Audiol. 2011;22(6):342-58.

20. Carvalho NG, Novelli CVL, Colella-Santos MF. Performance of school-aged children in the basic audiological evaluation and the binaural integration task. Audiol., Commun. Res. 2018;23:e2016.

21. Matos GGO, Frota S. A influência das perdas auditivas sensorioneurais na ordenação temporal. Rev. CEFAC. 2013;15(6):1435-40.

22. Mendes SC, Branco-Barreiro FCA, Frota S. Masking level difference: reference values in adults. Audiol., Commun. Res. 2017;22:e1746.

23. Jerger $\mathrm{S}$, Jerger J. Alterações auditivas: um manual para avaliação clínica. São Paulo: Atheneu; 1989.

24. Nunes C, Pereira L, Carvalho G. Scale of Auditory Behaviors and auditory behavior tests for auditory processing assessment in portuguese children. CoDAS. 2013;25(3):209-15.

25. Musiek F. Frequency (pitch) and duration patterns tests. J Am Acad Audiol. 1994;5(4):265-8.

26. Sartori AATK, Delecrode CR, Cardoso ACV. (Central) auditory processing in schoolers in initial literacy grades. CoDAS. 2019;31(1):1-8. 
27. Santos TS, Mancini PC, Sancio LP, Castro AR, Labanca L, Resende LM. Findings in behavioral and electrophysiological assessment of auditory processing. Audiol., Commun. Res. 2015;20(3):225-32.

28. Bamiou D, lliadou V, Zanchetta S, Spyridakou C. What can we learn about auditory processing from Adult Hearing Questionnaires? J Am Acad Audiol. 2015;26(10):824-37.

29. Souza IMP, Carvalho NG, Plotegher SDCB, ColellaSantos MF, Amaral MIR. Auditory processing screening: contributions of the combined use of questionnaire and auditory tasks. Audiol., Commun. Res. 2018;23(8):1-8.

30. Barry J, Tomlin D, Moore D, Dillon H. Use of Questionnaire-Based Measures in the assessment of listening difficulties in school-aged children. Ear and Hear. 2015;36(6):300-13.

31. Aghazadeh J, Mahdavi ME, Tahaei AA, Tabatabaee SM. Inter-list equivalency and reliability of the Persian randomized dichotic digits test. Aud Vest Res. 2015;24(2):71-9.

32. Musiek FE, Baran JA, Pinheiro ML. Behavioral and electrophysiological test procedures. In: Musiek FE, Baran JA, Pinheiro ML (orgs). Neuroaudiology: case studies. San Diego: Singular Publishing Group; 1994. p. 7-28.

33. Prabhu P, Seshadri D, Ganeshan A, Babu L. Test-retest reliability of Kannada time-compressed speech test and time-compressed monosyllables test. Hearing, Balance and Communication. 2016;14(3):111-6.

34. Prabhu P, Sujan M, Rakshith S. Effect of compression ratio on perception of time compressed phonemically balanced words in Kannada and monosyllables. Audiology Research. 2015;5(1):34-7.

35. Braga OH, Fernandes L, Estrela RH, Aragão-Dantas AC. Auditory evoked potentials in individuals with congenital hypothyroidism: a systematic review of scientific literature. Rev Ciênc Méd Biol. 2013;12(4):486-91.

36. Masip V. Fonética e fonologia portuguesas: um modelo didático latoratorial. Linha D'Água. 2015;28(1)173-92.

37. Silva CS. Consonant cluster acquisition: a comparative study. Porto das Letras. 2016;2(1):7-21.

38. Aguiar LB, Souza EK, Evangelista CKS, Nunes ADS, Lima KRA, Balen SA. Influence of the socieconomic level on the temporal resolution hearing skills in adults. Rev. CEFAC. 2019;21(4):1-8. 